\title{
USING PICTURE BOOKS TO ENHANCE MOTIVATION AND LANGUAGE LEARNING OF REMEDIAL EFL LEARNERS
}

\author{
Arisa Kochiyama \\ Associate Professor/ Wayo Women's University, Japan \\ Email: kochiyama@wayo.ac.jp
}

APA Citation: Kochiyama, A. (2015). Using picture books to enhance motivation and language learning of remedial EFL learners. Indonesian EFL Journal, 1(1), 10-16

Abstract: According to studies done by the Japanese Ministry of Education, Culture, Sports, Science and Technology, many secondary schools across the nation aren't adequately preparing students to excel at college. Universities are stepping in to fill the gap by offering remedial college courses in subjects such as Japanese and English. The purpose of the present study is to explore how an EFL class for college freshmen can help the students develop the critical thinking skills as well as language skills such as pronunciation, vocabulary and grammar necessary to read at the college level.

Picture books are often overlooked by adult ESL/EFL instructors as many of them feel uncomfortable reading books designed for children. However, if chosen with consideration for the interests of the students and used in ways that are appropriate for adult learners, picture books can provide valuable opportunities of language-rich experiences and interactions. In fact a number of studies in Western cultures have shown that picture books provide a wealth of possibilities for teaching English topics as well as various vocabulary sets such as family, food, clothes, and so on. They can also motivate learners to read more and learn more as the students are more likely to find reading a manageable challenge.

Given these functions of picture books, the main objectives of the study are (1) to discuss the merits of using picture books in remedial English classes from the viewpoint of English language learning, (2) to investigate the effect of using picture books on the learners' motivation and emotional development, and (3) to give a report about the students' reactions towards an adoption of a picture book in an EFL class.

Keywords: intercultural communication, English as a second language, EFL classroom, language and gender, children's literature in EFL learning

\section{INTRODUCTION \\ Remedial Students}

The Education Rebuilding Implementation Council, an expert panel under Prime Minister Shinzo Abe, has suggested that the government lower the grade when primary school students start studying English from the fourth year and make it a regular subject for fourth, fifth and sixth graders. Since the 2011 academic year, a "foreign language activity" has become a required course at primary schools and now, fifth- and sixth-graders take English classes once a week, which has guaranteed 8 years of English education. Despite these national efforts to strengthen the early English education, many students have difficulty in learning English as a school year rises. According to the survey conducted on ninth-graders by Education, Culture, Sports, Science and Technology in
$2009,18.6 \%$ of the students feel they "have somehow fallen behind" in their English class, and $9.6 \%$ feel they "have completely fallen behind" in their English class (Kiyota 2009). In addition, the results of the survey conducted by Benesse Education Research and Development Center show that $60 \%$ of the junior high school students feel "they are not good at English" (Kiyota 2009). In fact, the academic skill level of college students has become a problem and many universities have already adopted remedial classes for those underprepared students to ensure a basic understanding of the subjects.

\section{Learning Environment of Japanese EFL Students}

One of the biggest issues which accompanies learning English in the EFL environment is that learners have limited 
exposure to English in daily life. Little opportunity to use English makes it hard for learners to find a reason to study the language; in other words, they are not motivated to study the target language (Otsuki and Takase 2012). Additionally, with the grammartranslation method, the most common approach adopted at secondary schools across Japan, learners are easy to lose motivation for studying English. In this method the emphasis is put on translating English text into Japanese word by word, rather than appreciating the content of the text (Otsuki and Takase 2012). Moreover, the main goal of English education is for students to succeed in passing the entrance examination to higher education, which mainly consists of grammar-oriented questions and comprehension questions of short difficult passages (Otsuki and Takase 2012). Many of the underprepared collage students have failed in learning EFL in their introductory stage in junior high schools and had English phobia for a long period of time as a school year rises and grammar and vocabulary become more complicated and difficult. The results of the survey conducted by Benesse Education Research and Development Center show that $78.6 \%$ of the junior high school students who fall behind in their English class have found "studying English grammar too difficult" and 72.2\% have found "studying English too stressful"(Kiyota 2009). It is evident that the social and education circumstances surrounding English education in Japan have generated unmotivated and reluctant students.

\section{Picture Books}

In recent years a number of researchers suggest authentic children's literature as an alternative to the traditional bottom-up approach to EFL. For example, Ghosn (2002) offers the following good reasons for using authentic children's literature; first, children's literature provides a motivating context for language learning since learners are naturally drawn to stories; second, literature can contribute to language learning as it presents natural language, language as its finest, and can thus foster vocabulary development in context; third, literature can function as a change agent; good literature deals with some aspects of the human condition, and can thus contribute to the emotional development of the learners and foster positive interpersonal and intercultural attitudes. Similarly Ellis and Brewster (2002) suggest that using children's literature can help develop positive attitude towards the foreign language, culture and language learning; using stories allows the teachers to introduce or revise new vocabulary and sentence structures by exposing the children to language in varied, memorable and familiar contexts, which will enrich their thinking and gradually enter their own speech. They also emphasize the importance of reading aloud by pointing out that listening to stories helps learners become aware of the rhythm, intonation and pronunciation of language.

Given the above findings, the purpose of the study is to investigate the merits of using picture books in remedial English classes in terms of enhancing learners' language learning, motivation to learn English and improve their emotional development.

\section{METHOD}

To address the questions regarding the merits of using picture books in a classroom, the following investigations will be made: (1) A picture book titled The Paper Bag Princess will be investigated in terms of the introduction of particular grammatical features and vocabulary. (2) A pilot study will be conducted to investigate the effect of using picture books on the learners' motivation and emotional development. And (3) the students' reactions towards an adoption of the picture book in an EFL class will be analyzed.

\section{RESULTS AND DISCUSSION Selecting an Appropriate Picture Book: Input Hypothesis and Picture Books}

It has been widely accepted in the EFL teaching context that input plays more important role than output. According to Krashan's (1981) Input Hypothesis, an essential factor for language acquisition is input that is comprehensible but that also contains language structures beyond the learner's current proficiency level. In addition, he claims that the input hypothesis has been 
successfully applied in the area of reading. Muranoi (2006) discusses four points to facilitate learners' second language learning: (a) Comprehensible input; second language learners acquire the language by hearing and understanding messages that are slightly above their current target language level. (b) Relevance; texts should contain language forms and cultures relevant to learners to match the learners' interest. (c) Authenticity; input should be culturally and linguistically authentic, which provides the natural use of certain essential grammatical feature in communication. (d) Aural-written input; written and aural input should be well combined.

Keeping in mind the length and the level of difficulty as well as the students' interest in the context, a picture book titled The Paper Back Princess is used in the present study. The book has been selected because (1) it is written in simplified beginning-level English, which is parallels the language competence of a local junior high school graduate, (2) it tells interesting, sophisticated and critical story that learners of all ages can enjoy, (3) it contains colorful illustrations, which can be great motivators for struggling or reluctant readers, (4) it is available at many bookstores and public libraries, and (5) it can be used as alternative reading. In fact, The Paper Bag Princess written by a Canadian author Robert Munsch is a children's book whose story reverses the prince and princess stereotype and has won critical acclaim from feminists. Although children's literature such as picture books, chapter books and fairy tales is commonly used in the reading practices in ESL/EFL classrooms, many researchers point out that gender bias is still prevalent in contemporary children's and young adult literature (Kuo 2005). As a result, teachers need to be sensitive to their materials or they will easily fall in to a passive acceptance of everything literature presents to us (Fox 1993). Reading The Paper Bag Princess is likely to empower students with critical thinking and alternative reading while improving their literacy.

In terms of the level of difficulty of The Paper Bag Princess, the learners need 150 words to read the text. Since Japanese junior high school students have learned 900 English words, junior high school graduates can understand the overall meanings of the text using the twenty percent of the knowledge of English vocabulary. In terms of the grammatical features, the text includes the majority of grammatical items that are suggested for junior high school students to be learned, which are stated in the guideline made by the Japanese Ministry of Education, Culture, Sports, Science and Technology. The tenses used in the text include present tense, present progressive, past tense, past progressive, and present perfect. Sentence structures used in the text include affirmative sentences, negative sentences, interrogative sentences, imperative sentences and comparison. To-infinitives and passive voices are used as well. Examples of each grammatical items appeared in the text are as follows:

Present

I am a very busy dragon.

Present Progressive

You smell like ashes, your hair is all tangled and you are wearing a dirty old paper bag.

Past

Elizabeth was a beautiful princess.

She lived in a castle and had expensive princess clothes.

Past Progressive

She was going to marry a prince named Ronald.

Present Perfect

Well, a princess! I love to eat princesses, but $\underline{I}$ have already eaten a whole castle today.

Negative (Past)

They didn't get married after all.

Interrogative

Is it true that you are the smartest and fiercest dragon in the whole world?

Imperative

"Wait," shouted Elizabeth.

Comparison

Is it true that you are the smartest and fiercest dragon in the whole world?

She shouted as loud as she could, "Hey, dragon!"

To-infinitive

When he got back he was too tired to talk, and he lay down and went straight to sleep.. 
Passive Voice

Come back when you are dressed like a real princess.

In the text, a variety of vocabulary, idioms, and expressions repeat themselves, which enables learners to read similar or same words and grammatical structures over and over without noticing it and develop both grammatical and communicative competence. Rivers (1968) points out the effectiveness of pattern drills on foreign language learning discussing that habits are strengthened by reinforcement and analogy provides a better foundation for foreign language learning than analysis.

\section{Repetition}

(1) A. The dragon stuck his nose out of the door and said, "Well, a princess! I love to eat princesses, but I have already eaten a whole castle today. I am a very busy dragon. Come back tomorrow."

B. The dragon stuck his nose out of the door and said, "Go away. I love to eat princesses, but I have already eaten a whole castle today. I am a very busy dragon. Come back tomorrow."

(2) A. "Is it true," said Elizabeth, "that you can burn up ten forests with your fiery breath?"

B. Elizabeth said, "Dragon, is it true that you can fly around the world in just ten seconds?"

Examples A and B in Sentences (1) which appear in a page apart illustrate the repetition of the same phrases and sentences. Examples A and B in Sentence (2) appear in two pages apart. The same sentence structures are used in this examples but not the same vocabulary. It should be noticed, however, that a word "ten" is used repeatedly in the sentences, which helps learners to acquire the word naturally. According to Gannon (1987) who has investigated the merits of picture books in English education, repetition is one of the most familiar features of children's literature. Repetition not only adds rhythm and the mysterious charm of ritual to the simplest verbal formulas but clarifies the structure of narrative for young readers and helps them to remember what they have read.

Given the above findings, it is likely that The Paper Bag Princess may serve as an alternative to EFL textbooks and have the effect on remedial learners' EFL learning from the viewpoint of Input Hypothesis.

\section{Emotional Development: Pilot Study}

Since the 1960's, language educators in the United States have made it a priority to incorporate the study of culture into their classroom curricula. Through the study of other languages, learners gain a knowledge and understanding of culture that uses the language. In fact, learners cannot truly master the language until they have also mastered the cultural contexts in which the language occurs (Peterson and Coltrane 2003). Brooks (1964) proposes five meanings of culture to be combined in language teaching: growth, refinement, fine arts, patterns of living, and a total way of life. The fourth meaning refers to the role of the individual in life situations of every kind and his conformity to the rules and models for attitude and conduct in them.

According to Brooks, this meaning is the most immediately useful in instruction. Literary texts are often replete with cultural information and evoke memorable reactions for readers. Texts that are carefully selected for a given group of students and with specific goals in mind can be very helpful in allowing students to acquire insight into a culture (Peterson and Coltrane 2003). One study compared the level and quality of recollection when two different groups of students learned about Cote D'Ivoire (Scott and Huntington 2000). One group studied a fact sheet and a second studied a poem about colonialism in Cote D'Ivoire. The researchers found that the group that read the poem showed a capacity to empathize with the personal history of the Cote D'Ivoire people. Thus, culture must be fully incorporated as a vital component of language learning. Second language teachers should identify key cultural items in every aspect of the language that they teach.

Given these findings, a pilot study was conducted to investigate the effect of using a picture book on the learners' motivation and emotional development. The subjects of the study consist of 28 Japanese high beginning EFL learners with Japanese as their first language. They are either sophomores or juniors majoring English Communication in a private women's university located in the center of Japan. Reading tasks of reading aloud, translation, and students' written feedback and semi-structured interviews developed by 
BC Teacher's Federation were provided for three consecutive 90 minute classes. The purpose of the reading tasks is to allow students not only to learn the target language but also to think critically about how men and women are portrayed and compare these portrayals to their own lives. It is hoped that the discussion of such a controversial issue lead by the discussion questions can stimulate students to foster critical thinking and literacy and empower them with a future understanding of gender notions in their lives (Kuo 2005). Kuo (2005) claims the importance of teacher's role by pointing out that teachers need to be extremely aware of the fact that dominant reading practices will make students accustomed to mainstream texts and as a result students will passively identify themselves with the characters in the stories. Kuo suggests that teachers should equip students with a certain stance that deliberately challenges the text and help students uncover the gender inequalities present in the text, in doing so, it is useful for teachers to adopt resistant or oppositional reading practices rather than dominant and conventional reading practices. According to the $\mathrm{BC}$ Teacher's Federation, a familiar starting point for students would be to read traditional fairy tales and identify the elements that make it different from a non-fiction story by asking open-ended questions as in the following:

1) How are princesses usually portrayed at the start of a story?

2) Is she waiting around for something or someone to come to her rescue or make her happy? If so, whom?

3) Towards the end of a story what makes Cinderella and Snow White happy? Why do you think that might be?

After reading a variety of traditional and modernized fairy tales and analyzing components of each style of fairy tale, teachers can ask students:

4) In you world, who is a more realistic character? Why do you think that? Who does each princess remind you of in real life?

5) Can a prince or princess be single and live happily ever after? Why or why not? Do you know anyone who is single and happy?

As for the possible extensions, BC
Teacher's Federation suggests the following strategies:

6) Have students take a traditional fairy tale and work together in small groups to write a new ending for it. Ask them to create one where the princess and prince live in a more realistic and independent manner.

(BC Teacher's Federation)

Questions 1) to 3) help students to be aware of stereotyped representations embedded in the traditional fairy tales such as Snow White, Cinderella, Sleeping Beauty, and so on.

Questions 4) to 6) help students to rethink about gender notions of the characters in The Paper Bag Princess and foster critical thinking and literacy. The students' answers are shown as follows:

1)

\section{Poor} 22

Beautiful, Pretty

Bullied, Life-threatened、 Facing hardship $\quad 10$

Kind, Gentle

Unhappy

Doing housework/cleaning

Cheerful

Quiet

Single-minded

2) Being saved by the prince $\quad 25$

Being happy 14

Being rich

Nothing particular

3) Getting married with a prince $\quad 25$ Being saved by a prince 19

Being rich/Living in plenty 11

Being without a villain $\quad 8$

4)

Elizabeth

Traditional princesses

Reasons for Elizabeth

She didn't get married after all 9

She is a person of action $\quad 6$

She is strong/brave 6

She is not pretty

She looks at the prince's personality

5)

Yes

Reasons

I know those are single and happy

Marriage does not always lead to happiness 
Different plot is more interesting

NO

Reasons

Marriage is the happy ending

Happy marriage is a dream

The above report shows that the alternative reading conducted in the classes was successful in helping students become aware of gender bias prevalent in traditional fairy tales and approach the text from multiple perspectives and with alternative attitudes.
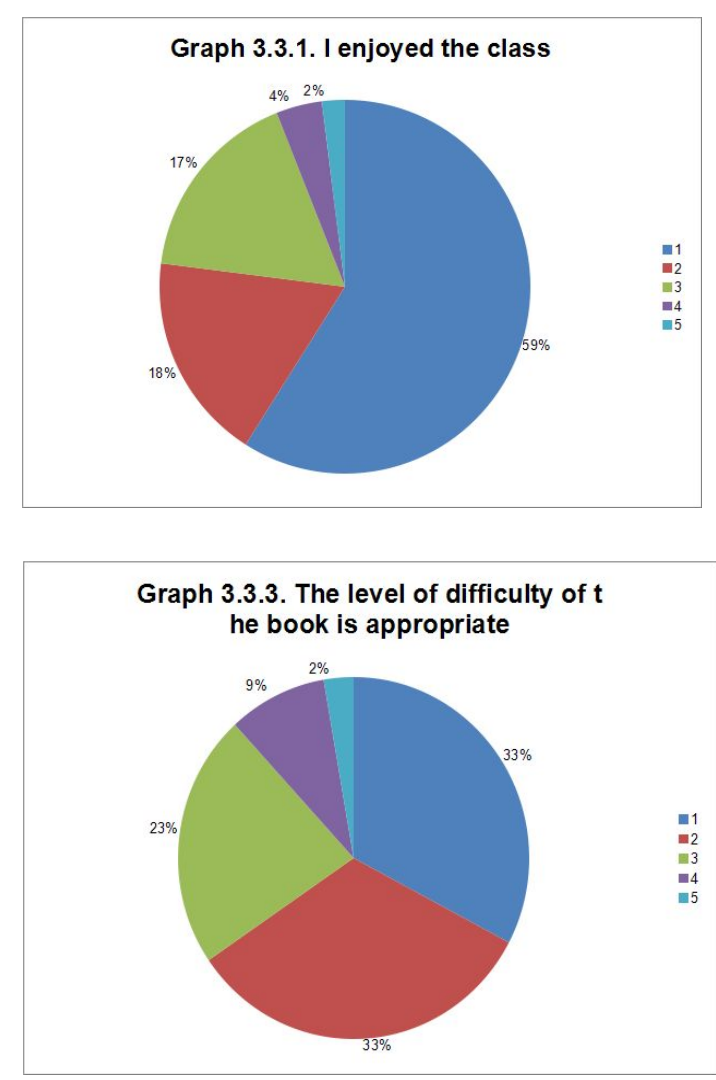

The pie charts above show the positive reactions of the students towards reading The Paper Bag Princess in their EFL classes as $77 \%$ of the students enjoyed the classes and $75 \%$ of them have become more interested in the target culture than before. As for the difficulty of the text, $66 \%$ of the students think the text has matched the students' proficiency level. In addition, $56 \%$ of the students think that the continuous reading of picture books in the future will enhance their English proficiency. Thus the above results show that reading children's picture book has motivated the EFL learners to study the target language.

\section{Motivation}

In order to investigate the effects of the use of picture books on the learners' motivation for learning English, the students' reactions towards reading The Paper Bag Princess in the classes have been analyzed with 4 questions (see Graphs 3.3.1 2.2.4.). The scale is strongly agree $=1$, agree $=2$, neither agree nor disagree $=3$, disagree $=4$, strongly disagree $=5$.

\section{Graph 3.3.2 I have beomce more inter ested in the target culture than before}

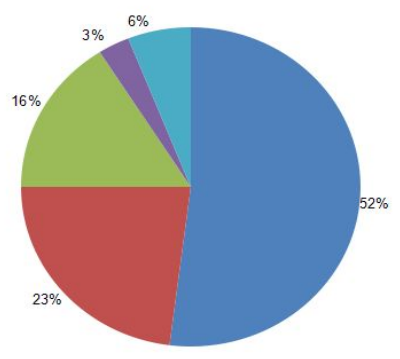

\section{Graph 3.3.4. Continuous reading of $\mathrm{pi}$ cture books will enhance English prof} iciency

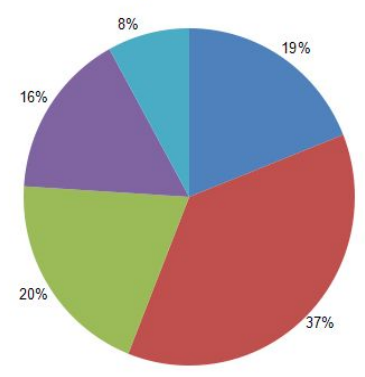

\section{CONCLUSION}

The present study have investigated the merits of using picture books in remedial English classes in terms of enhancing learners' language learning, motivating to learn the language and improving their emotional development. The results of the study have suggested that the text should be carefully selected in terms of the level of difficulty such as vocabulary and grammar use and the story should be interesting enough for adult learners. The carefully selected literature may serve as a viable alternative to EFL textbooks in reading classes because they give students opportunities to learn not only language skills but also to be sensitive to different cultures. 


\section{Arisa Kochiyama}

Using Picture Books to Enhance Motivation and Language Learning of Remedial EFL Learners

Quality literature and activities can also help learners gain insight into human behavior, and it can stimulate students to foster critical thinking and literacy and empower them with a future understanding of gender notions in their lives (Kuo 2005).

In order to better understand the effect of using picture books on learners' emotional development, further analysis on the students' report about The Paper Bag Princess is required. With increased importance placed on remedial classes in universities, it would seem beneficial for additional research to be conducted in quantitative study as well as qualitative one to determine the effects of picture books presented in class.

\section{References}

http://bctf.ca/uploadedFiles/Public/SocialJoustice/Iss ues/LGBTQ/FairyTalesGender.pdf.

(Retrieve May 20, 2014)

Brooks, N. (1964). Language and Language Learning. New York: Brace and World.

Ellis, G. \& Brewster, J. (2002). Tell It Again! The new Storytelling Handbook for Primary Teachers.

Harlow: Pearson Education.

Fox, M. (1993). Men who weep, boys who dance: The gender agenda between the lines in children's

literature. Language Arts 70, 84-88.

Ghosn, I. K. (2002). Four good reasons to use literature in primary school ELT. ELT journal. 56 (2), 172-179.
Gannon, S. R. (1987). One more time: Approaches to repetition in children's literature. Children's

literature association quarterly 12 (1), 2-5.

Kiyota, Y. 2009. Motivation of remedial EFL learners: A case study of Japanese collage EFL learners. Education Research on Remedial Education 4 (2), 41-47.

Krashan, S. (1981). Second Language Acquisition and Second Language Learning. Oxford: Pergamon.

Kuo, J. (2005). Teaching ESL/EFL student to recognize gender bias in children's literature. The

internet TESL journal. http://iteslj.org/Articles/Kou-GenderBias.html.

Lazar, G. (1993). Literature and language teaching: A guide for teachers and trainers. Cambridge:

Cambridge University Press.

Munsch, R. 2011. The paper bag princess. Toronto: Annick Press.

Muranoi, H. (2006). Effective English Teaching and Learning Methods from the Viewpoint of Second Language Acquisition Studies. Tokyo. Taishukan.

Otsuki, K., \& Takase, A. (2012). Comparison of pedagogical grammar in picture books and English

textbooks. Extensive Reading World Congress Proceedings 1, 116-119.

Peterson, E. \& Coltrane, B. (2003). Culture in second language teaching. CAL Digest. Washington,

DC: Center for Applied Linguistics. Retrieve May 20, 2014, from http://www.cal.org/resources/digest/0309peters on.html

Rivers, W. (1968). Teaching Foreign Language Skills. Chicago: University of Chicago Press.

Scott, M., \& Huntington, A. (2000). Reading culture: Using literature to develop C2 competence.

Foreign Language Annals, 35 (6), 622-631 